\title{
Directionality and spread of shallow water waves along the eastern Arabian Sea
}

\author{
V. Sanil Kumar and T. R. Anoop \\ Ocean Engineering, CSIR-National Institute of Oceanography (Council of Scientific \& Industrial Research), Dona Paula, \\ Goa, 403 004, India
}

Correspondence to: V. Sanil Kumar (sanil@ nio.org)

Received: 4 March 2013 - Revised: 24 August 2013 - Accepted: 23 September 2013 - Published: 25 October 2013

\begin{abstract}
The directional characteristics of shallow water waves are described based on measured data during 2011 at two locations spaced at $350 \mathrm{~km}$ along the eastern Arabian Sea. Study shows that, for high swells (significant wave height $>1 \mathrm{~m}$ ) approaching almost parallel to the coast, the difference between mean and principal wave direction at spectral peak is negligible. The directional spreading of wind-sea-dominated wave spectrum is less than that of the swell-dominated spectrum. Average value of the ratio of the directional width at twice the peak frequency and that at the peak frequency is 1.9 indicating that the directional width increased at higher frequency. Even though both locations studied are along the eastern Arabian Sea, there are more northwest waves due to shamal events and local winds found at the northern location $(27 \%)$ than at the southern location $(7 \%)$.
\end{abstract}

Keywords. History of geophysics (ocean sciences) - meteorology and atmospheric dynamics (waves and tides)

\section{Introduction}

A complete representation of a sea state requires information on the wave direction and associated directional spreading of the spectrum (Brissette and Tsanis, 1994). The directional spreading of sea states is an important design parameter in offshore engineering. Wave directionality affects the resulting wave kinematics and results in change in the forces exerted on offshore structures (Adcock and Taylor, 2009). Designers are provided with bulk estimates of wave height, period and direction, and analytic models for wave directional spectra are used to generate representative wave conditions for engineering applications (Lee et al., 2010). The wave energy distribution in frequency and direction is given by the directional spectrum, which can be represented as the product of the frequency spectrum and directional spreading function (Borgman, 1982). A number of parametric models are used to estimate the directional spreading function (Longuet-Higgins et al., 1963; Borgman, 1982; Donelan et al., 1985; Kobune and Hashimoto, 1986; Zhang and Zhang, 2006). When bimodal seas are present, use of parametric methods of estimating the directional distribution function will result in the shortcoming inherent to programs. Modelfree methods such as maximum likelihood method (MLM), maximum entropy method (MEM) (Borgman, 1982), iterated maximum likelihood method (IMLM) (Pawka, 1983), extended maximum entropy method (EMEM) (Hashimoto et al., 1993) do not have such limitation because the estimate of directional spreading function at each individual frequency is independent of the rest of the spectrum and do not depend on a spreading parameter (Alves and Melo, 1999).

In most parametric models, mean wave direction is an input parameter and two different approaches are used to determine the wave direction. One involves the use of first-order Fourier coefficients (mean wave direction, $\theta$ ), while the other uses second-order Fourier coefficients (principal wave direction, $\varphi$ ). Based on the analysis of directional data, Goda et al. (1981), Kuik et al. (1988), Benoit (1992) and Besnard and Benoit (1994) concluded that $\theta$ is the most representative index to describe the wave direction. Kumar and Anand (2004) found that $\theta$ and $\varphi$ corresponding to the peak frequency covary with a correlation coefficient of 0.99 for a location off Goa at $23 \mathrm{~m}$ water depth. However, $\theta$ and $\varphi$ corresponding to higher $(>0.25 \mathrm{~Hz})$ and lower $(<0.07 \mathrm{~Hz})$ frequencies are not similar. There have been very few studies on directional spreading of shallow water waves (Alves and Melo, 1999; Herbers et al., 1999; Kumar et al., 1999, 2000; Kumar, 2006; 
Deo et al., 2002; Pettersson and Kahma, 2005). Another parameter used to estimate the directional spreading function is the spreading parameter $(s)$. The waters off the west coast of India are exposed to seasonally reversing winds, with winds from the southwest (SW) direction during the SW (summer) monsoon period (June to September) and from the northeast (NE) during the NE (winter) monsoon period (October to January). The period between NE and SW monsoon is the pre-monsoon period or the fair weather $(\mathrm{FW})$ period. The seasonal changes in winds produce similar changes in the directional spreading parameter, and the nature of the seasonal variability is not studied. Also the variation of the directional spreading in a day due to the influence of sea/land breeze has not been studied in the past and the spatial variation of the spread parameter along the eastern Arabian Sea. In this article, directional characteristics of shallow water waves during a one-year period at two open ocean locations spaced at $350 \mathrm{~km}$ along the eastern Arabian Sea are studied based on simultaneous measurements carried out using moored directional waverider buoys. In addition, directional spreading of wind sea and swell is examined. Glejin et al. (2013a) studied the influence of winds on temporally varying short and long period gravity waves in the nearshore regions of the study area. The non-directional wave spectral characteristics of this area have been studied by Kumar et al. (2013).

\section{Study area}

One location off Honnavar (southern location) at $9 \mathrm{~m}$ water depth (geographic position $14.3042^{\circ} \mathrm{N}, 74.3907^{\circ} \mathrm{E}$ ) and another location off Ratnagiri (northern location) at $13 \mathrm{~m}$ water depth (geographic position $16.9801^{\circ} \mathrm{N}, 73.2584^{\circ} \mathrm{E}$ ) situated in the eastern Arabian Sea are selected for the study (Fig. 1). Distances of the locations from the west coast of Indian mainland are $2.5 \mathrm{~km}$ at Honnavar and $2 \mathrm{~km}$ at Ratnagiri. Distance between the two locations is around $350 \mathrm{~km}$, and both locations are subjected to swells from Indian Ocean. Along the study area, the SW monsoon winds are strong and the rainfall of the region during SW monsoon varies from 2.6 to $3.1 \mathrm{~m}$ (Mishra et al., 2004). The rainfall during SW monsoon is $80-90 \%$ of the annual rainfall (Koteswaram, 1976). Large variation in the wave climate is unlikely at the two locations studied since a substantial part of the wave energy at these locations is due to the swells (Glejin et al., 2013a; Sajiv et al., 2012). The waves in the study area are influenced by local winds (Glejin et al., 2013a) and the shamal events (Aboobacker et al., 2011; Glejin et al., 2013b). Based on the measured wind speed using autonomous weather station at Ratnagiri, Glejin et al. (2013a) reported that sea breeze during pre- and post-monsoon season varies between 1 and $3 \mathrm{~m} \mathrm{~s}^{-1}$, whereas land breeze strength is always less than $1 \mathrm{~m} \mathrm{~s}^{-1}$. The observed direction of the sea breeze is from the NW and that of the land breeze is NE.

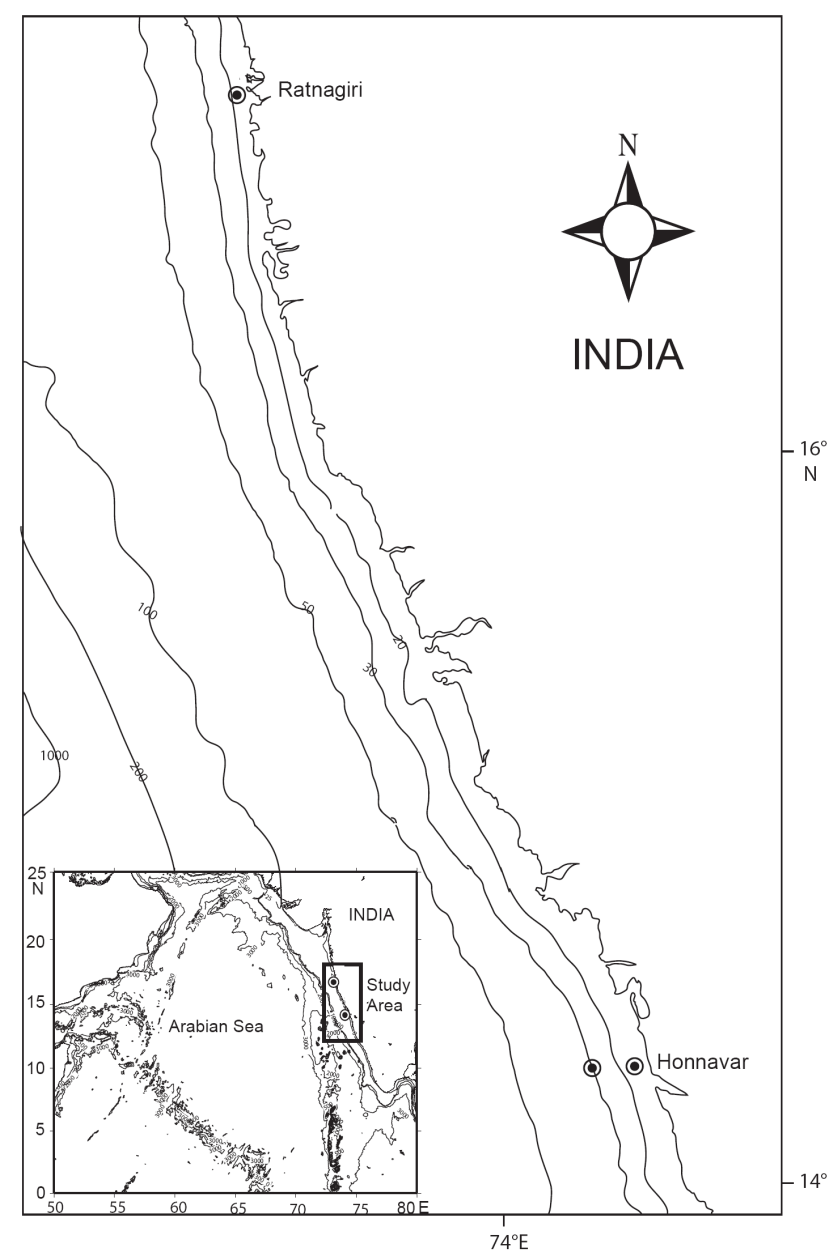

Fig. 1. Study area showing the locations of wave measurements off Ratnagiri and Honnavar. The depth contours are in meters.

\section{Materials and methods}

Waves were measured using the Datawell directional waverider buoy (Barstow and Kollstad, 1991) from 1 January to 31 December 2011. Measurements were made in coordinated universal time (UTC), the time referred to in the paper. The vertical and horizontal (eastward and northward) displacement data were obtained from the respective accelerations measured by the buoy. The data were recorded continuously at $1.28 \mathrm{~Hz}$, and the data for every $30 \mathrm{~min}$ were processed as one record. The collected time series was subjected to standard error checks for spikes, steepness and constant signals (Haver, 1980), and a total of 17421 records measured simultaneously at each location were used for further analysis. The wave spectrum was obtained through fast Fourier transform (FFT). FFTs of 8 series, each consisting of 256 measured vertical elevations of the buoy data, were added to obtain the spectrum. High-frequency cut-off was set at $0.58 \mathrm{~Hz}$, and the resolution was $0.005 \mathrm{~Hz}$. Significant wave height $\left(H_{m 0}\right)$, which equals $4 \sqrt{m_{0}}$, was obtained from the spectral moment, 
where $\mathrm{m}_{0}$ is the zero-order spectral moment. The period corresponding to the maximum spectral energy (i.e., peak wave period $\left(T_{\mathrm{p}}\right)$ was obtained from the wave spectrum. Mean wave direction $(\theta)$ and principal wave direction $(\varphi)$ are estimated as below (Kuik et al., 1988).

$\theta(f)=\arctan \left[b_{1}(f) / a_{1}(f)\right]$

$\varphi(f)=0.5 \arctan \left[b_{2}(f) / a_{2}(f)\right]$,

where $a_{1}, b_{1}, a_{2}$ and $b_{2}$ are the first four Fourier coefficients of the directional distribution function and are determined as follows:

$a_{1}(f)=\frac{Q_{z x}(f)}{k(f) \cdot C_{z z}(f)}$

$b_{1}(f)=\frac{Q_{z y}(f)}{k(f) \cdot C_{z z}(f)}$

$a_{2}(f)=\frac{C_{x x}(f)-C_{y y}(f)}{k(f)^{2} \cdot C_{z z}(f)}$

$b_{2}(f)=\frac{2 C_{x y}(f)}{k(f)^{2} \cdot C_{z z}(f)}$,

where $C_{x x}, C_{y y}$ and $C_{z z}$ represent the auto-spectra, $C_{z x}$ the co-spectra and $Q_{z x}$ the quadrature spectra between variables $z$ and $x, C_{x y}$ the co-spectra between variables $x$ and $y, Q_{z y}$ the quadrature spectra between variables $z$ and $y$, $k=\sqrt{\frac{C_{x x}(f)+C_{y y}(f)}{C_{z z}(f)}}$ is the wave number determined from the auto-spectra. Variables $z, x$ and $y$ represent the three translational (vertical, north-south and east-west) motions of the directional waverider buoy.

Directional spreading is studied using directional width $(\sigma)$ as given by Kuik et al. (1988) and mean spreading angle $\left(\theta_{k}\right)$ and long-crestedness parameter $(\tau)$ as per Goda et al. (1981). Directional width is calculated using the firstorder Fourier coefficients $\left(a_{1}, b_{1}\right)$, and the mean spreading angle is determined using first- as well as second-order Fourier coefficients $\left(a_{2}, b_{2}\right)$.

$\sigma=\sqrt{2\left(1-r_{1}\right)}$

$\theta_{k}=\arctan \left[\frac{\sqrt{0.5 b_{1}^{2}\left(1+a_{2}\right)-a_{1} b_{1} b_{2}+0.5 a_{1}^{2}\left(1-a_{2}\right)}}{a_{1}^{2}+b_{1}^{2}}\right]$

$\tau=\left[\frac{1-\sqrt{a_{2}^{2}+b_{2}^{2}}}{1+\sqrt{a_{2}^{2}+b_{2}^{2}}}\right]^{1 / 2}$

$r_{1}=\sqrt{\left(a_{1}^{2}+b_{1}^{2}\right)}$
Wave age is estimated as $C_{\mathrm{p}} / U$, where $C_{\mathrm{p}}$ is the wave phase speed at peak frequency and $U$ is wind speed. Reanalysis data of zonal and meridional components of wind speed at $10 \mathrm{~m}$ height real-time observations at $6 \mathrm{~h}$ intervals from NCEP/NCAR (Kalnay et al., 1996) are used to analyze the wind pattern. These data are provided by the NOAACIRES Climate Diagnostics Center, Boulder, Colorado, at http://www.cdc.noaa.gov/.

\section{Results and discussions}

\subsection{Wave directional spreading}

For long-crested waves, the value of directional width is $0^{\circ}$, and as the waves become short-crested, the value increases and the wave directional spreading increases. During the SW monsoon period, average value of the directional width is less ( $15^{\circ}$ at Honnavar and $19^{\circ}$ at Ratnagiri) than that during remaining period of the year $\left(27^{\circ}\right.$ at Honnavar and $29^{\circ}$ at Ratnagiri). Relatively large values of directional width observed during the pre- and post-monsoon period are due to the co-existence of swells and seas in the study area (Glejin et al., 2013a; Kumar et al., 2012, 2013; Sajiv et al., 2012). Directional spreading is narrowest with low values at the spectral peak frequency $\left(f_{\mathrm{p}}\right)$ and broadened at frequencies both higher and lower than $f_{\mathrm{p}}$ (Fig. 2). Average value of the ratio of the directional width at twice the peak frequency and that at the peak frequency is 1.9 indicating that the directional width increased at higher frequency. Minimum value of directional width observed at spectral peak is similar to the earlier observations (Mitsuyasu et al., 1975; Hasselmann et al., 1980). During the SW monsoon period, the low values of directional width are confined to a narrow frequency range $(0.08-0.15 \mathrm{~Hz})$ since the peak frequency is in a narrow range (Fig. 2). During the pre-monsoon period (FebruaryMay), the low values of the directional width is either at low frequencies or at high frequencies depending on the predominance of swell or wind sea. When the swell is predominant, the directional width is low at lower frequencies, and when wind sea is predominant, the directional width is low at higher frequencies (Fig. 2). A significant wave height up to $4.2 \mathrm{~m}$ is observed during the study period (Kumar et al., 2013). The non-directional wave spectral characteristics of the study are presented in Kumar et al. (2013).

The directional width referred to hereafter is the value at spectral peak frequency. Values of directional width are relatively lower (annual average $=23.7^{\circ}$ ) at the southern location compared to the northern location (annual average $=25.3^{\circ}$ ). According to Snell's law, both the mean wave angle (mean departure of wave propagation directions from shore normal) and the directional spread (range of wave angles) decrease with decreasing depth (Henderson et al., 2006). The directional spread parameter is lower at $9 \mathrm{~m}$ water depth than that at $13 \mathrm{~m}$ water depth due to the shoaling of the waves (Herbers 

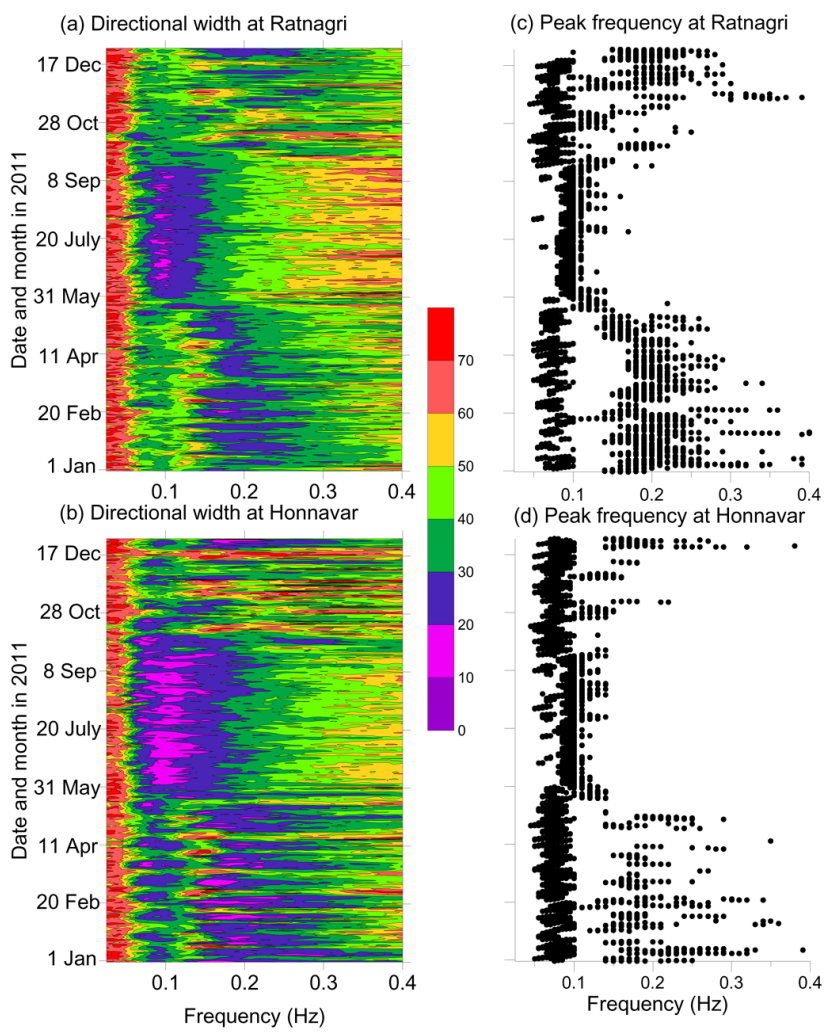

Fig. 2. Variation of (a) directional width at Ratnagiri, (b) directional width at Honnavar, (c) peak frequency at Ratnagiri, and (d) peak frequency at Honnavar during 2011. Unit of directional width is in degrees.

et al., 1999). Anoop et al. (2013) observed that wave reflection is relatively higher at Ratnagiri than that at Honnavar, and the increase in wave reflection causes an increase of directional spread (Ardhuin and Roland, 2012) at Ratnagiri.

The wave data available simultaneously at 30 and $9 \mathrm{~m}$ water depth off Honnavar from 22 October to 17 November 2012 are examined to know the variation in directional width at different water depths. The wave height is slightly lower at $9 \mathrm{~m}$ than at $30 \mathrm{~m}$ (Fig. 3a). The mean wave direction at $9 \mathrm{~m}$ is in a narrower range $\left(210-250^{\circ}\right)$ than $\left(190-250^{\circ}\right)$ at $30 \mathrm{~m}$ water depth due to refraction (Fig. 3b). Kumar et al. (2013) showed that, depending on the wave period, waves from $210^{\circ}$ in deep water change to direction of $217-241^{\circ}$ at $9 \mathrm{~m}$ water depth off Honnavar. During the measurement period, the average directional width at both depths is $22^{\circ}$ (Fig. 3c).

Directional spectrum is narrow with low values of directional width for single peaked spectrum, and a high value of directional width is observed for broad-banded spectrum (Fig. 4). Hence, the low values of directional width found at the southern location are also due to the larger number of single peaked spectra $(63 \%)$ at this location compared to that $(46 \%)$ at the northern location (Kumar et al., 2013). Few



Fig. 3. Comparison of wave parameters (significant wave height, mean wave direction and directional width) at 30 and $9 \mathrm{~m}$ water depth off Honnavar.

( $2 \%$ of the time) high values $\left(>50^{\circ}\right)$ of directional width are found at the southern location associated with $H_{m 0}<1 \mathrm{~m}$. The directional width for high waves $\left(H_{m 0}>2 \mathrm{~m}\right)$ is less with an average value of $17^{\circ}$ compared to the annual average value of $24^{\circ}$ (Fig. 5a). For waves with $H_{m 0}>3 \mathrm{~m}$, the average value of directional width is $15^{\circ}$ at the northern location and $11^{\circ}$ at the southern location. Based on worldwide field measurements of directional spreading, Forristall and Ewans (1998) showed the representation of storms as unimodal sea states with relatively small directional spreading. The present study shows that directional width of the swells $\left(T_{\mathrm{p}}>8 s\right.$ with $H_{m 0}<2 \mathrm{~m}$ is high $\left(>30^{\circ}\right)$ and that for wind sea $\left(T_{\mathrm{p}}<8 s\right)$ is less than $40^{\circ}$ (Fig. $5 \mathrm{~b}$ ). The directional spreading of wind-sea-dominated wave spectrum is less (average directional width $=18^{\circ}$ ) than that of the swell-dominated spectrum (average directional width $=24^{\circ}$ ). The high directional width for a swell-dominated spectrum is because the sea state 


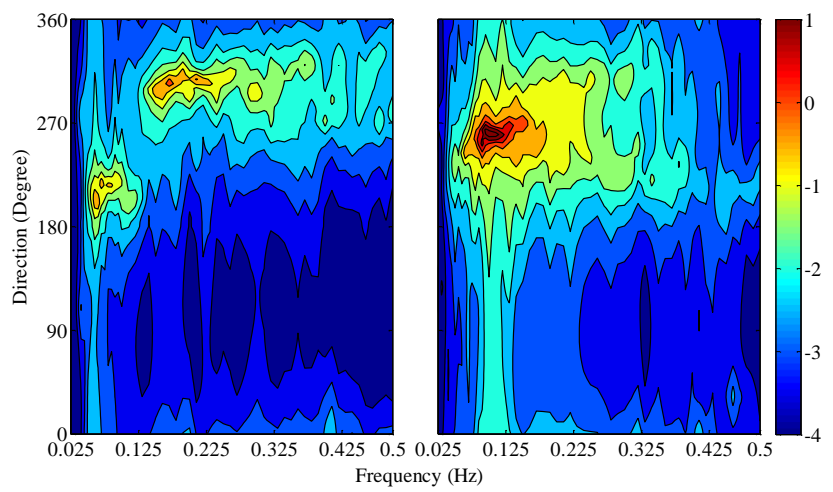

(a) 2 April $20111930 \mathrm{~h}$

(b) 7 July $20110350 \mathrm{~h}$

Fig. 4. Typical (a) broad- and (b) narrow-banded directional wave spectra at Honnavar. Value of directional width is $42^{\circ}$ for (a) and $11.5^{\circ}$ for (b). Contours presented are the spectral energy density $\left(\mathrm{m}^{2} \mathrm{~Hz}^{-1} \mathrm{deg}^{-1}\right)$ in logarithmic scale.

contains wind waves along with the swells. Large difference in values of directional width is not observed for wind-seadominated and swell-dominated wave spectra in the present case since the measured data consist of wind seas and swells. Average coastal inclination is $17^{\circ} / 15^{\circ}$ to the west from the true north at Honnavar/Ratnagiri, and hence $253 / 255^{\circ}$ waves are parallel to the coast. The spreading of waves approaching parallel to the coast $\left(240\right.$ to $\left.270^{\circ}\right)$ is less $\left(<15^{\circ}\right)$ than those arriving from other directions (Fig. 5c). Lee et al. (2010) found that multi-directional random wave spectra will become more directionally asymmetric in shallower water due to the difference in refraction of directionally symmetric components. The waves with mean wave direction more than $270^{\circ}$ are the wind-sea-dominated waves or the shamal swells, and the directional widths for these waves are less than $40^{\circ}$. The waves with mean wave direction less than $240^{\circ}$ are predominantly swells, and the directional widths of these waves are more than $40^{\circ}$. Figure $5 \mathrm{c}$ indicates that the directional spread of SW waves is higher than those arriving from the $\mathrm{W}$ and NW. Even though the SW waves are the swells with low wave height and the swells are narrow-banded, the higher value of directional spread observed for the $\mathrm{SW}$ waves is due to the co-existence of wind sea during this period (Fig. 5c). Forristall and Ewans (1998) reported that directional spread at the peak frequency is about $10^{\circ}$ for swells and $30^{\circ}$ for wind seas.

The half-hourly variation of directional width in a day is large during the pre- and post-monsoon seasons $\left(\approx 24^{\circ}\right.$ at Ratnagiri and $36^{\circ}$ at Honnavar) compared to SW monsoon period $\left(\approx 14^{\circ}\right.$ at Ratnagiri and $13^{\circ}$ at Honnavar). The large variation in directional width during the pre- and post-monsoon seasons during a day is due to the influence of sea/land breeze (Glejin et al., 2013a). The influence of sea/land breeze caused large variation $(7 \mathrm{~s})$ in peak wave period in a day during the pre- and post-monsoon season compared to the variation $(3 \mathrm{~s})$ during the $\mathrm{SW}$ monsoon period.
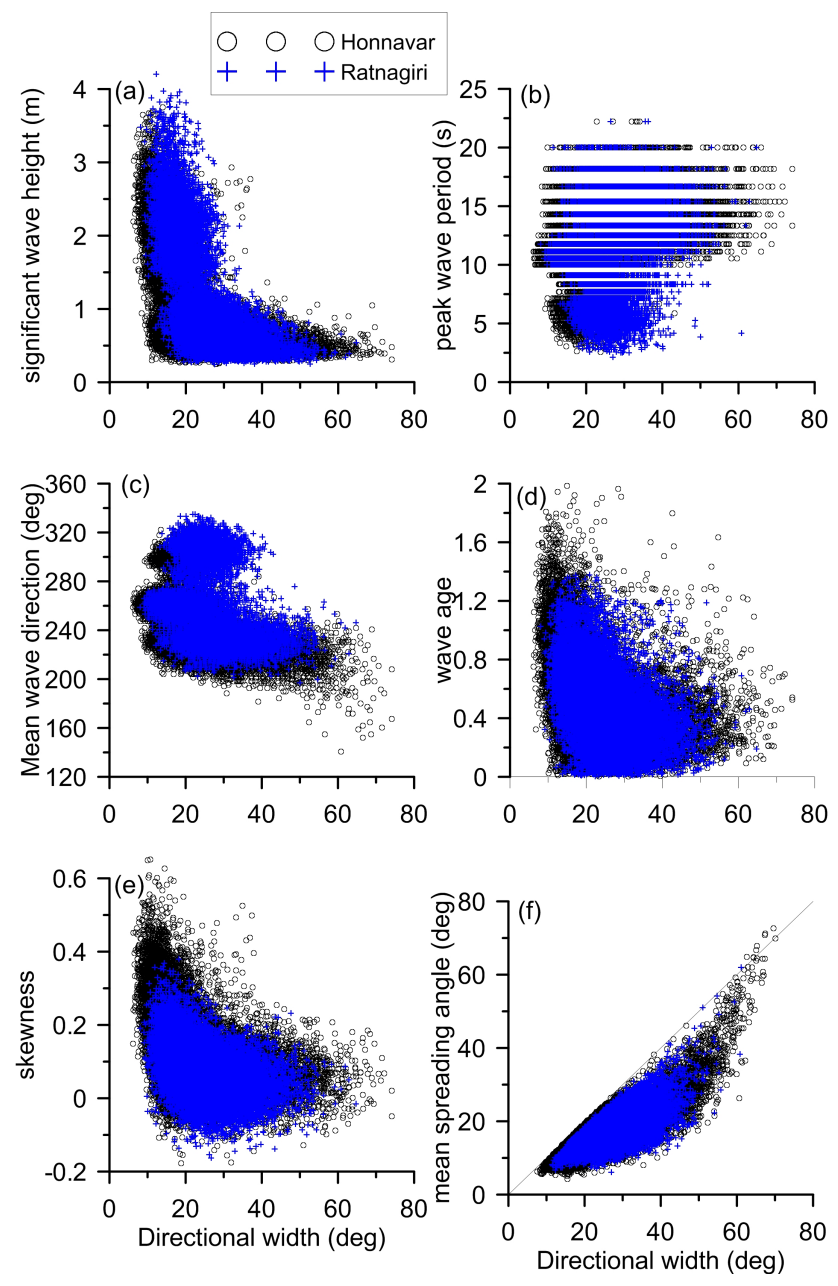

Fig. 5. Variation of directional width with (a) significant wave height, (b) peak wave period, (c) mean wave direction, (d) wave age, (e) skewness of the surface elevation, and (f) mean spreading angle.

The hourly average value of directional width during different months indicates that the variation is large $\left(\approx 16^{\circ}\right)$ during November and December and is the least $\left(\approx 1.5^{\circ}\right)$ during June (Fig. 6). The low variation in directional width observed from June to September is because during this period the waves are predominantly parallel to the coast and the variation in peak frequency is minimum (Fig. 2c and d). The study shows that high values of directional width are associated with lower wave age values (Fig. 5d). Since the wave age is based on NCEP/NCAR wind data with a large spatial interval, the sea/land breeze influences are not included in the wave age values. Banner and Young (1994) indicated that the directional spread decreases slightly as wave age increases. Mitsuyasu et al. (1975) and Hasselmann et al. (1980) reported decreasing spreading with decreasing inverse wave age, but Donelan et al. (1985) and Ewans (1998) do not find a clear dependence. Pettersson and Kahma (2005) found that narrow fetch data have higher inverse wave age than broad 




Fig. 6. Hourly variation of monthly averaged significant wave height and directional width at Honnavar.

fetch data. It is found that the directional width is less for highly positively skewed surface elevation (Fig. 5e). The high sea states are positively skewed, and hence the value of directional width is low for highly positively skewed surface elevation.

Apart from directional width, another parameter used to study the measure of the energy spread around a mean direction of wave propagation is the mean spreading angle. Generally the mean spreading angle varies from 0 to $90^{\circ}$ and will be 0 for unidirectional waves. For both locations studied, values of $\sigma$ are larger than those of $\theta_{k}$ (Fig. 5f) similar to the earlier observations (Goda et al., 1981; Benoit, 1992 and Besnard and Benoit, 1994; Kumar, 2006). Average value of $\sigma$ is 25.3 and $23.7^{\circ}$ for Ratnagiri and Honnavar, and the corresponding value of $\theta_{k}$ is 17.1 and $15.8^{\circ}$. The average value of $\theta_{k}$ is lower in the southern location than that at the northern location similar to the observations for $\sigma$. High value $\theta_{k}$ is found at the southern location $2 \%$ of the time over the annual period associated with $H_{m 0}<1 \mathrm{~m}$.

Another parameter required by the designers is the spreading parameter $s$ used in the theoretical directional spreading function (cosine power $2 \mathrm{~s}$ ). The directional spreading function is narrower and more peaked for larger value of the spreading parameter $s$. The annual average value of $s$ is slightly lower $(\approx 12)$ at the northern location than that $(\approx 20)$ at the southern location. The reason for lower values of $s$ at the northern location is due to the presence of a larger number of wind waves compared to the southern location. For high waves $\left(H_{m 0}>2 \mathrm{~m}\right)$, the parameter $s$ is 23 and 36 at the northern and southern location. Kumar (2006) reported average value of spreading parameter for different shallow water locations around India as 16, 20, 28 and 29. For deep water waves, Goda (1985) has recommended a maximum spreading parameter value of 10 for wind waves, 25 for swell with short decay, and 75 for swell with long decay distance. For swell-dominated waves, the value of parameter $s$ is 18 and 24 for the northern and southern locations and is close to the recommended value of 25 by Goda (1985). The value of $s$ found in the present study is higher than the common value $(s=12)$ used for practical purposes (Tucker and Pitt, 2001).

\subsection{Wave direction}

Wave direction with respect to coastal inclination determines the direction of movement of littoral sediments in the nearshore region. Also, in most directional spreading functions, wave direction is taken as an input parameter determined either based on first-order Fourier coefficients (mean wave direction, $\theta$ ) or based on second-order Fourier coefficients (principal wave direction, $\varphi$ ). Difference between $\theta$ and $\varphi$ at spectral peak is relatively large (up to $40^{\circ}$ ) at Honnavar compared to at Ratnagiri (Fig. 6a and b). The directional spreading is minimum (low values of directional width) for waves having smaller difference between $\theta$ and $\varphi$ (Fig. 6c and d). The difference between $\theta$ and $\varphi$ at spectral peak is large for $H_{m 0}$ less than $1 \mathrm{~m}$ (Fig. 6e and f) and is negligible $\left(<5^{\circ}\right)$ for $H_{m 0}$ more than $1 \mathrm{~m}$. The directional width is large $\left(\sim 60^{\circ}\right)$ for the waves from $\theta p<240^{\circ}$ with $H_{m 0}<1 \mathrm{~m}$, and the difference between $\theta$ and $\varphi$ is large $\left(20-40^{\circ}\right)$ for these waves (Fig. 7d). The study shows that the difference between $\theta$ and $\varphi$ at spectral peak is large for long period waves $\left(T_{\mathrm{p}}>12 \mathrm{~s}\right)$ with small wave height $\left(H_{m 0}<1 \mathrm{~m}\right)$ from 200 to $240^{\circ}$. Based on the analysis of directional data, Goda et al. (1981), Kuik et al. (1988), Benoit (1992) and Besnard and Benoit (1994) concluded that $\theta$ is the most representative index to describe the wave direction. Kumar and Anand (2004) found that $\theta$ and $\varphi$ corresponding to the peak frequency co-vary with a correlation coefficient of 0.99 . However, the mean wave direction and principal wave direction corresponding to higher $(>0.25 \mathrm{~Hz})$ and lower $(<0.07 \mathrm{~Hz})$ frequencies are not similar. Large differences between $\theta$ and $\varphi$ are found in the high-frequency region where wave energies are comparatively small. Lee et al. (2010) found that the difference between the mean direction and the peak direction $\left(\theta_{\mathrm{p}}-\varphi_{\mathrm{p}}\right)$ is indicative of the skewness of the directional distribution. During the SW monsoon period, at Honnavar and Ratnagiri, waves are predominantly swells from southwestwest $\left(255-258^{\circ}\right)$ direction (Kumar et al., 2013), and during this period the difference between $\theta$ and $\varphi$ is negligible. 
Table 1. Predominant wave direction corresponding to the spectral peaks at both locations during different months (values in parentheses are the percentage occurrence).

\begin{tabular}{|c|c|c|c|c|c|c|}
\hline \multirow[t]{2}{*}{ Month } & \multicolumn{3}{|c|}{ Ratnagiri } & \multicolumn{3}{|c|}{ Honnavar } \\
\hline & 1 peak & 2 peak & 3 peak & 1 peak & 2 peak & 3 peak \\
\hline January & $315(73.5)$ & $225(23.5)$ & $270(2.6)$ & $225(75.8)$ & 315 (17.7) & $270(5.9)$ \\
\hline February & $315(58.2)$ & $225(35.9)$ & $270(6.0)$ & $225(66.3)$ & 315 (26.6) & $270(5.5)$ \\
\hline March & $315(61.7)$ & $225(36.2)$ & $270(2.0)$ & $225(75.3)$ & $315(15.2)$ & $270(6.0)$ \\
\hline April & $225(51.5)$ & $315(46.5)$ & $270(2.0)$ & $225(88.2)$ & $315(7.1)$ & $270(2.8)$ \\
\hline May & $225(40.0)$ & $270(39.3)$ & $315(20.7)$ & $225(71.8)$ & $270(21.6)$ & 315 (5.4) \\
\hline June & $270(99.8)$ & & & $270(99.2)$ & & \\
\hline July & $270(99.2)$ & & & $270(95.0)$ & $225(5.0)$ & \\
\hline August & $270(97.7)$ & $225(2.3)$ & & $270(80.5)$ & $225(19.5)$ & \\
\hline September & $270(71.7)$ & $225(28.3)$ & & $270(55.7)$ & $225(44.3)$ & \\
\hline October & $225(85.0)$ & $315(12.0)$ & $270(3.0)$ & 225 (98.6) & & \\
\hline November & $225(85.5)$ & $315(8.1)$ & $270(6.4)$ & $225(91.5)$ & $270(7.1)$ & $180(1.3)$ \\
\hline December & $315(48.7)$ & $225(45.3)$ & $270(5.9)$ & $225(82.5)$ & $315(13.2)$ & $270(2.1)$ \\
\hline All months & $270(36.4)$ & $225(36.2)$ & $315(27.4)$ & $225(59.8)$ & $270(32.1)$ & $315(7.0)$ \\
\hline
\end{tabular}

Figure 8 shows frequency plots of wave period and direction. Two well-defined peaks are observed at both locations during the pre- and post-monsoon season due to the presence of seas (from 290 to $330^{\circ}$ ) and swells (from 180 to $210^{\circ}$ ) in the study area. These peaks represent the long period waves that originated in the southern Indian Ocean, far away from the coast and the seas generated close to the coast by local winds (Glejin et al., 2013a) and the shamal events (Aboobacker et al., 2011; Glejin et al., 2013b). During the SW monsoon, the peaks are merged to a common period (8-12s) and are from 240 to $250^{\circ}$ and from 270 to $280^{\circ}$. Over the annual cycle, at the northern location, there are three predominant wave directions: W, SW and NW with 36.4, 36.2 and $27.4 \%$ of occurrence (Table 1). However, at the southern location, only two predominant wave directions are found: SW during $59.8 \%$ and $\mathrm{W}$ during $32.1 \%$ of the time. Even though both locations studied are along the eastern Arabian Sea, there are more NW waves due to shamal events (Aboobacker et al., 2011; Glejin et al., 2013b) and local winds (Glejin et al., 2013a) found at the northern location $(27 \%)$ than at the southern location $(7 \%)$. The west coast of India is open to the south Indian Ocean and the Southern Ocean, and hence swells are present throughout the year along this coast. But the study shows that, during an annual cycle, the predominance of SW waves is less at the northern location compared to the southern location.

\subsection{Directional spectrum}

There are different methods for estimating directional spectrum from the time-series data and the performances of each method depend on data type. Hashimoto et al. (1993), based on numerical test cases, found that extended maximum entropy method (EMEM) better estimates directional spectrum for single point measuring system. Since we used the data from a single point measuring system (i.e., the wave rider buoy), EMEM is used for estimation of directional spectrum. To study the directional wave characteristics, the monthly averaged directional spectrum is obtained from the half-hourly data collected at the northern location. Averaged directional wave spectrum shows the predominance of swells (8-12s) along the study area during SW monsoon season with direction mainly from $\mathrm{W}$ (Table 1). The distinguishing characteristic of SW monsoon months is the absence of double-peaked spectra (Fig. 9). In all other months either partially separated or fully separated double-peaked spectra are present, and the secondary peak becomes predominant during the pre-monsoon season (February to May) due to the presence of seas and swells. From January to March and during December, the primary peak is from the NW and is predominantly due to the wind sea. During April-May and OctoberNovember, the primary peak is from the SW and is due to the swells. During October and November the swell component in the double-peaked spectrum becomes dominant and partially separated. Compared to SW monsoon season, the spectral energy in all other months is low.

\section{Directional bimodality of the sea state}

Directional bimodality has been observed in most of the studies conducted in the past $50 \mathrm{yr}$ (Phillips, 1958; Cote et al., 1960; Holthuijsen, 1983; Jackson et al., 1985; Brissette and $\mathrm{Wu}, 1992$; Young et al., 1995; Wyatt, 1995; Ewans, 1998; Wyatt and Van der Vlugt, 1999). However, due to inadequate resolutions of the earlier spatial measurement instruments and controversy over the method-dependent estimations of directional distribution using temporal measurements, the directional bimodality remains an intriguing but 

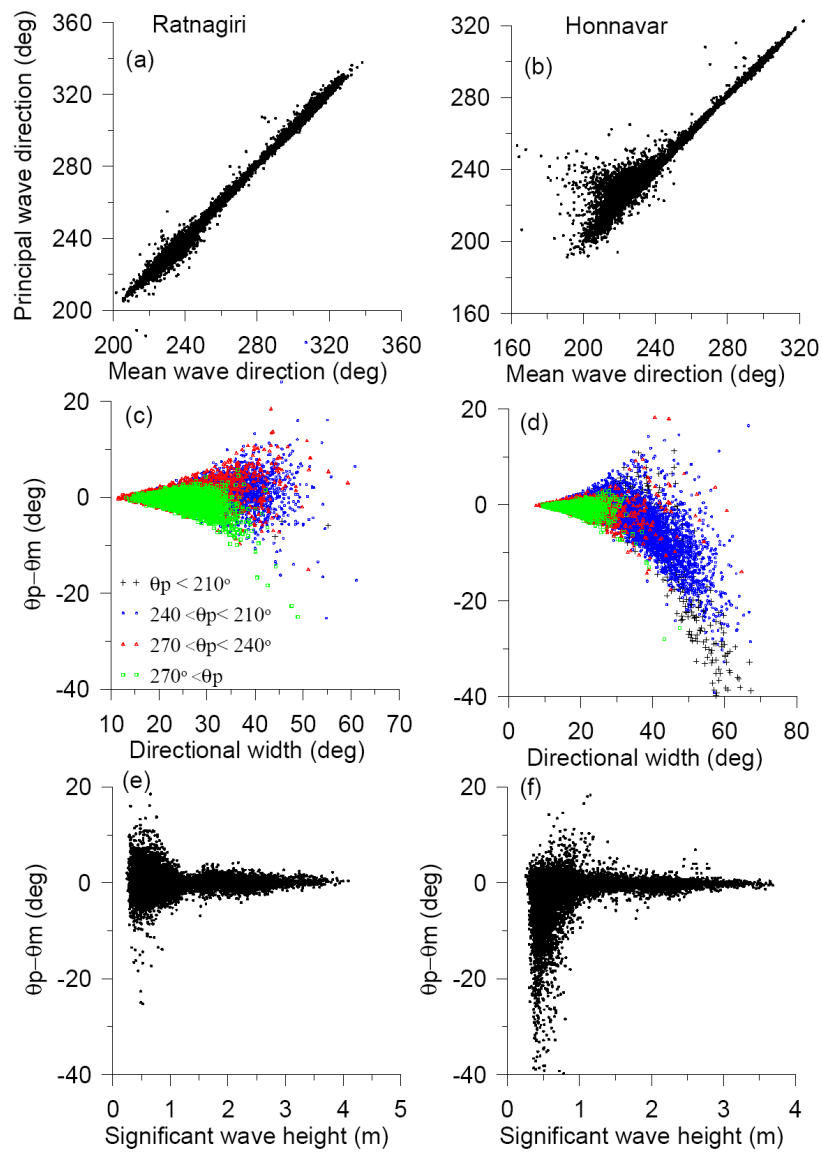

Fig. 7. Variation of principal wave direction and mean wave direction at (a)Ratnagiri and (b) at Honnavar, difference between principal and mean wave direction with directional width (c) at Ratnagiri and (d) at Honnavar, difference between principal and mean wave direction with significant wave height (e) at Ratnagiri and (f) at Honnavar.

less understood area of wind wave studies. The directional bimodality is the robust feature at the wave number above the spectral peak and is controlled mainly by the directional transfer of energy through nonlinear wave-wave interactions (Wang and Hwang, 2001). Goda et al. (1981) used longcrestedness parameter $(\tau)$ to study the directionality of the sea states. The long-crestedness parameter varies between 0 for uni-modal waves and 1 for waves with directional homogeneity. The average value of $\tau$ is 0.28 and 0.25 for the locations studied. The persistent nature of the directional bimodality indicates that the nonlinear wave-wave interaction mechanism not only actively moves wave energy away from the peak frequency into both higher and lower frequency components but also constantly redistributes wave energy into directions oblique to the wind direction. The bimodal directional distribution, unlike the uni-modal function, indicates that most wave energy is in two side lobes symmetrically or asymmetrically located about the peak wind direction. The bimodality of the directional distribution of the spectrum at frequencies lower and greater than the peak frequency is shown to be a strong feature of the sea states, which is consistent with high resolution field measurements (Gagnaire-Renou et al., 2010). The directional distribution at a particular time for four different frequencies shows that the spectral band width is minimum at peak frequency (Fig. 10b). Peak frequency $\left(f_{\mathrm{p}}\right)$ is $0.13 \mathrm{~Hz}$, and peak wave direction is $244^{\circ}$. The bimodality is observed to be significant at frequency $\left(\approx 2.2 f_{\mathrm{p}}\right)$ higher than the peak frequency (Fig. 10c and d). The characteristics of bimodality can be represented by the parameters such as lobe separation angle $\left(\theta_{\text {Lobe }}\right)$ and lobe ratio $\left(r_{\text {lobe }}\right)$. The lobe separation angle is the average of $\theta_{1}$ and $\theta_{2}$, where the angles $\theta_{1}$ and $\theta_{2}$ are defined as the angular separation distances of $\alpha_{1}$ and $\alpha_{2}$ from $\alpha_{0}$. Lobe ratio is the average of the ratios $D\left(f, \alpha_{1}\right) / D\left(f, \alpha_{0}\right)$ and $D\left(f, \alpha_{1}\right) / D\left(f, \alpha_{0}\right)$. For frequency at 2.077 times the peak frequency (Fig. 10c), $\theta_{\text {Lobe }}$ and $r_{\text {lobe }}$ are $41.54^{\circ}$ and 1.84 respectively, and those at frequency 2.278 times the peak frequency (Fig. 10d) are $71.21^{\circ}$ and 2.865. That means the directional bimodality increases with increasing frequency. The side lobes represented here as Lobe ${ }_{1}$ and Lobe $_{2}$ are asymmetrically located on both sides of peak wave direction. To quantify the asymmetric distribution, the ratio $R_{\mathrm{L}}\left(=D\left(f, \alpha_{2}\right) / D\left(f, \alpha_{1}\right)\right)$ of the two side lobes is calculated, and it is found as 2.28 and 1.64 for frequency at 2.077 and 2.278 times the peak frequency (Fig. 9c and d). The deviation of $R_{\mathrm{L}}$ from unity is an indication of an uneven energy distribution between the two side lobes. When the frequency increases, the asymmetry in energy distribution in lobes will decrease.

From this analysis, we conclude that the bimodal directional distribution is a distinctive and persistent feature over the higher frequency range. Here, the wave energy is distributed asymmetrically on the side lobes. The nearshore buoy location, where the peak wave direction is not in the local wind direction, possibly due to the slant fetch effect of the shoreline orientation and the less homogeneous and more fluctuating wind field that leads to the bimodal distribution, is much more asymmetric (Wang and Hwang, 2001), and maximum energy is distributed in the lobe near peak wave direction. The bimodality becomes more significant with increasing frequency, and this increase in bimodality indicates that the nonlinear wave-wave interaction increases with an increase in frequency. In the region of the peak frequency of the spectrum, the components are generally uni-modal, similar to the observations of Young et al. (1995). Correlation of the wave age with bimodal distribution parameters (longcrestedness parameter and mean spreading angle) is poor, indicating that the bimodal directional distribution is an invariant property of the wind-generated wave field (Ewans, 1998; Wang and Hwang, 2001). 


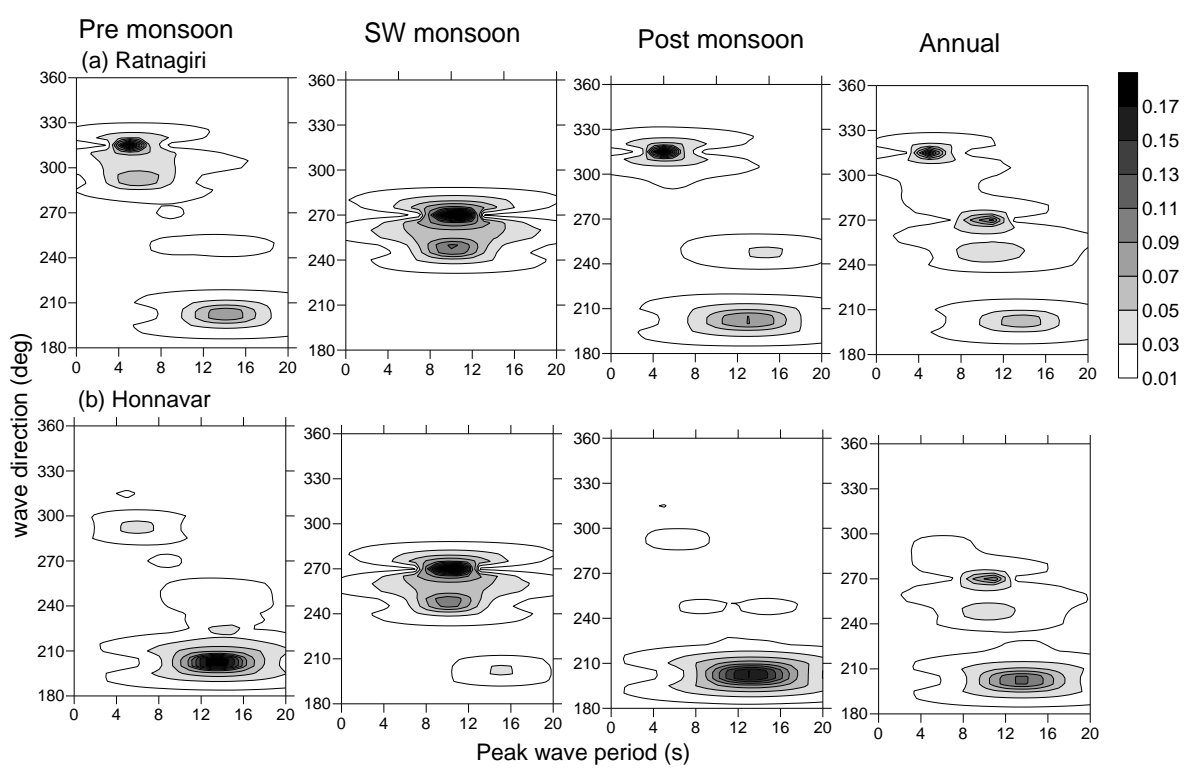

Fig. 8. Contour plot of frequencies of combined data for direction (degrees) and peak wave period $(s)$ in different seasons and annually. Top panel is for the northern location (Ratnagiri), and the bottom panel is for the southern location (Honnavar).
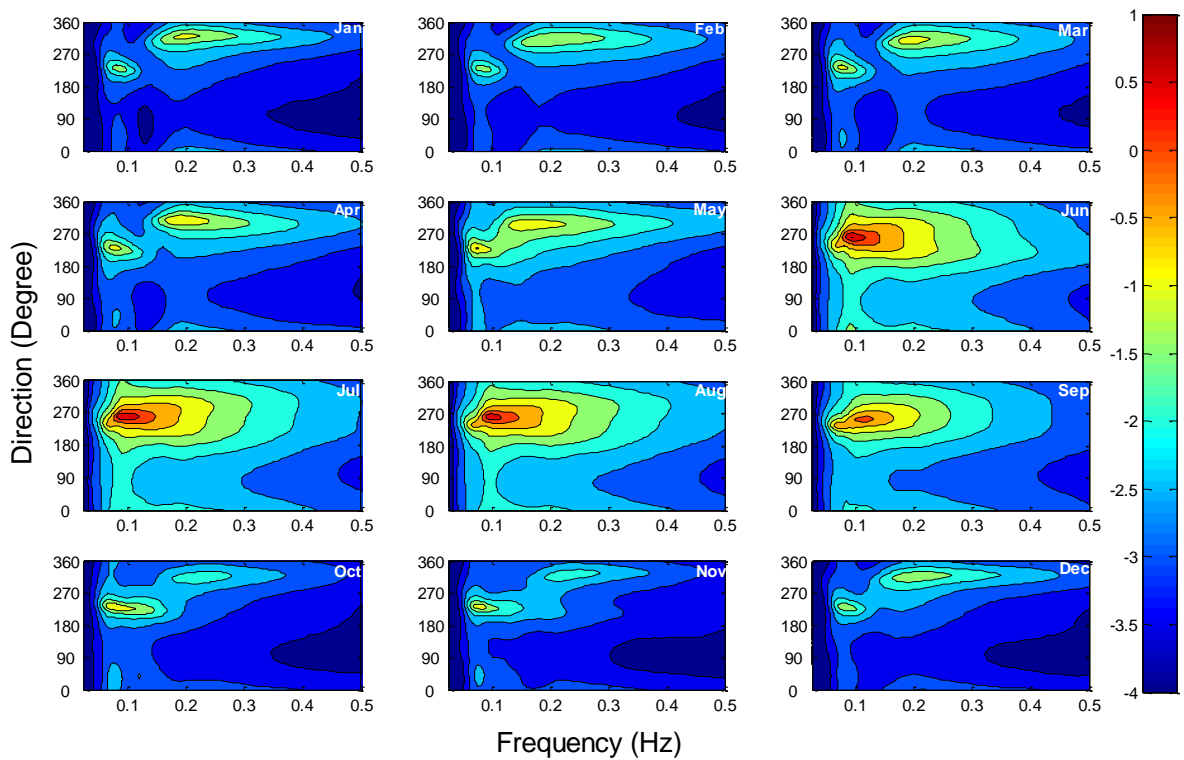

Fig. 9. Monthly averaged directional spectrum off Ratnagiri. Contours presented are the spectral energy density $\left(\mathrm{m}^{2} \mathrm{~Hz}^{-1} \mathrm{deg}-1\right)$ in logarithmic scale.

\section{Conclusions}

The study shows that, for high swells $\left(H_{m 0}>1 \mathrm{~m}\right)$ approaching almost parallel to the coast, the difference between mean and principal wave direction at spectral peak is negligible. The directional spreading of wind-sea-dominated wave spectrum is less (average directional width $=18^{\circ}$ ) than that of the swell-dominated spectrum (average directional width $=24^{\circ}$ ). Directional width at twice the peak frequency is 1.9 times the value at peak frequency. The variation of directional width in a day is large during the pre- and post-monsoon seasons due to the influence of sea/land breeze compared to SW monsoon period. Even though the two locations studied are in the eastern Arabian Sea spaced at a distance of $350 \mathrm{~km}$, the annual average value of directional spreading parameter $s$ is slightly lower (9.3) in the northern location than that (10.7) at the southern location due to the presence of a larger number of multi-peaked spectra at the northern location. The directional bimodality was observed to be significant at frequency 

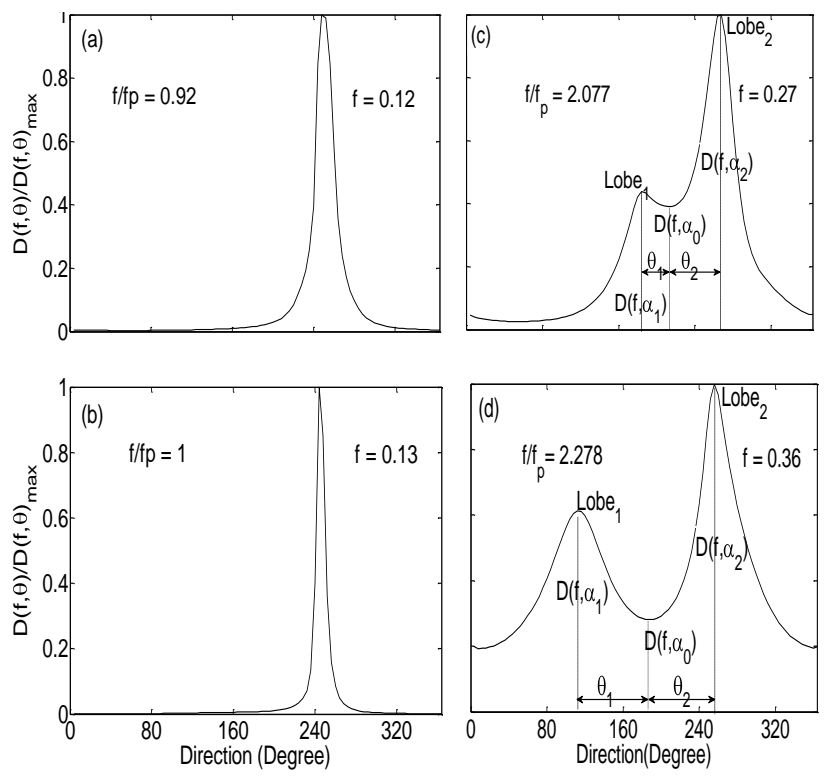

Fig. 10. Directional distribution at a particular time for frequencies $0.12,0.13,0.27$ and $0.36 \mathrm{~Hz}$.

$\approx 2.2$ higher than peak frequency. The distinguishing characteristic of SW monsoon period is the absence of doublepeaked directional spectrum, and in all other months either partially separated or fully separated double-peaked spectrum is present, and the secondary peak becomes predominant during the pre-monsoon season (February to May) due to the presence of mixed sea states. Over the annual cycle, at the northern location, there are three predominant wave directions: W, SW and NW with $36.4,36.2$ and $27.4 \%$ of occurrence. At the southern location, only two predominant wave directions are found: SW during $59.8 \%$ and $\mathrm{W}$ during $32.1 \%$ of the time. There are more NW waves due to shamal events and local winds found at the northern location (27\%) than at the southern location (7\%).

Acknowledgements. The authors gratefully acknowledge the financial support given by the Earth System Science Organization, Ministry of Earth Sciences, Government of India and Council of Scientific \& Industrial Research, New Delhi, to conduct this research. Directors of CSIR-NIO (Goa) and INCOIS (Hyderabad) provided encouragement to carry out the study. T. M. Balakrishnan Nair (Head) of Ocean Science \& Information Services Group, INCOIS (Hyderabad), initiated the wave measurements at Ratnagiri, and Jai Singh (Technical Assistant) from CSIR-NIO and Arun Nherakkol (Scientist) from INCOIS helped during the data collection. This work forms part of the Ph.D. thesis of the second author. This is NIO contribution No. 5457.

Topical Editor P. Drobinski thanks B. Jena and one anonymous referee for their help in evaluating this paper.

\section{References}

Aboobacker, V. M., Vethamony, P., and Rashmi, R.: "Shamal" swells in the Arabian Sea and their influence along the west coast of India, Geophys. Res. Lett., 38, 1-7, 2011.

Adcock, T. A. A. and Taylor, P. H.: Estimating ocean wave directional spreading from an Eulerian surface elevation time history, P. R. Soc. A, 465, 3361-3381, 2009

Alves, J. H. G. M. and Melo, E.: On the measurement of directional wave spectra at the southern Brazilian coast, Appl. Ocean Res., 21, 295-309, 1999.

Anoop, T. R., Kumar, V. S., and Glejin, J.: A study on reflection pattern of swells from the shoreline of peninsular India, Natural Hazards, submitted, 2013.

Ardhuin, F. and Roland, A.: Coastal wave reflection, directional spread, and seismoacoustic noise sources, J. Geophys. Res., 117, C00J20, doi:10.1029/2011JC007832, 2012.

Banner, M. and Young, I. R.: Modeling spectral dissipation in the evolution of wind waves, J. Phys. Oceanogr., 24, 1550-1561, 1994.

Barstow, S. B. and Kollstad, T.: Field trials of the directional waverider, in: Proceedings of the First International Offshore and Polar Engineering Conference III, 55-63, 1991.

Benoit, M.: Practical comparative performance survey of methods used for estimating directional wave spectra from heavepitch roll data, in: Proceedings of 23rd International Conference on Coastal Engineering American Society of Civil Engineers, Vol. 2, 62-75, 1992.

Besnard, J. C. and Benoit, M.: Representative directional wave parameters-Review and comparison on numerical simulation, International symposium, Waves Physical and numerical modelling IAHR, 901-910, 1994.

Borgman, L. E.: Maximum entropy and data-adaptive procedures in the investigation of ocean waves, in: Second workshop on maximum entropy and bayesian methods in applied statistics, Laramie, 111-117, 1982.

Brissette, F. P. and Tsanis, I. K.: Estimation of wave directional spectra from pitch-roll buoy data, J. Waterw. Port, C.-ASCE, 120, 93-115, 1994.

Brissette, F. P. and Wu, J.: Wave directional spectra and current interaction in Lake St, Clair, in: Proceedings of Third International Workshop on Wave Hindcasting and Forecasting, Montreal, PQ, Canada, 24-31, 1992.

Cote, L. J., Davis, J. O., Marks, W., McGough, R. J., Mehr, E., Pierson, W. J., Ropek, J. F., Stephenson, G., and Vetter, R. C.: The directional spectrum of a wind generated sea as determined from data obtained by the Stereo Wave Observation Project, Meteor Pap., 2, 88 pp., 1960.

Deo, M. C., Gondane, D. S., and Kumar, V. S.: Analysis of wave directional spreading using neural networks, J. Waterway, Port, Coast. Ocean Eng., 128, 30-37, 2002.

Donelan, M. A., Hamilton, J., and Hui, W. H.: Directional spectra of wind generated waves, Philos. T. Roy. Soc., 315, 509-562, 1985.

Ewans, K. C.: Observations of the directional spectrum of fetchlimited waves, J. Phys. Oceanogr., 28, 495-512, 1998.

Forristall, G. and Ewans, K.: Worldwide measurements of directional wave spreading, J. Atmos. Ocean Tech., 15, 440-469, 1998.

Gagnaire-Renou, E., Benoit, M., and Forget, P.: Ocean wave spectrum properties as derived from quasi-exact computations 
of nonlinear wave-wave interactions, J. Phys. Oceanogr., 115, C12058, doi:10.1029/2009JC005665, 2010.

Glejin, J., Sanil Kumar, V., Balakrishnan Nair, T. M., and Singh, J.: Influence of winds on temporally varying short and long period gravity waves in the near shore regions of the eastern Arabian Sea, Ocean Sci., 9, 343-353, doi:10.5194/os-9-343-2013, $2013 \mathrm{a}$.

Glejin, J., Kumar, V. S., Nair, T. M. B., Singh, J., and Mehra, P.: Observational evidence of summer Shamal swells along the west coast of India, J. Atmos. Ocean. Tech, 30, 379-388, doi:10.1175/JTECH-D-12-00059.1, 2013b.

Goda, Y.: Random seas and design of maritime structures, University of Tokyo Press, 420 pp., 1985.

Goda, Y., Miura, K., and Kato, K.: On-board analysis of mean wave direction with discus buoy, in: Proceedings International Conference on wave and wind directionality - Application to the design of structures, Paris, 339-359, 1981.

Hashimoto, N., Nagai, T., and Asai, T.: Extension of the maximum entropy principle method for directional wave spectrum estimation, Hydraul. Eng. Div. Mar. Hydrodyn. Div., 18, 232-246, 1993.

Hasselmann, D. E., Dunckel, M., and Ewing, J. A.: Directional wave spectra observed during JONSWAP 1973, J. Phys. Oceanogr., 10, 1264-1280, 1980.

Haver, S.: Analysis of uncertainties related to the stochastic modelling of ocean waves, Division of Marine structures, The Norwegian Institute of Technology, Report No. UR-80-09, 187, 1980.

Henderson, S. M., Guza, R. T., Elgar, S., and Herbers, T. H. C.: Refraction of Surface Gravity Waves by Shear Waves, J. Phys. Oceanogr., 36, 629-635, 2006.

Herbers, T. H. C., Elgar, S., and Guza, R. T.: Directional spreading of waves in the near shore, J. Geophys. Res., 104, 7683-7693, 1999.

Holthuijsen, L. H.: Observations of the directional distribution of ocean-wave energy in fetch-limited conditions, J. Phys. Oceanogr., 13, 191-207, 1983.

Jackson, F. C., Walton, W. T., and Peng, C. Y.: A comparison of insitu and airborne radar observations of ocean wave directionality, J. Geophys. Res., 90, 1005-1018, 1985.

Kalnay, E., Kanamitsu, M., Kistler, R., Collins, W., Deaven, D., Gandin, L., Iredell, M., Saha, S., White, G., Woollen, J., Zhu, Y., Leetmaa, A., Reynolds, B., Chelliah, M., Ebisuzaki, W., Higgins, W., Janowiak, J., Mo, K. C., Ropelewski, C., Wang, J., Roy, J., and Joseph, D.: The NCEP/NCAR 40-year reanalysis project, B. Am. Meteorol. Soc., 77, 437-471, 1996.

Kobune, K. and Hashimoto, N.: Estimation of directional spectra from the maximum entropy principle, in: Proceedings of the 5th International Offshore Mechanics and Arctic Engineering Conference, Tokyo, Japan, 1, 80-85, 1986.

Koteswaram, P.: Climatological studies of droughts in Asiatic monsoon area particularly India, in: Proceedings of Indian National Science Acadamy, 54, 1-14, 1976.

Kuik, A. J., Vledder, G., and Holthuijsen, L. H.: A method for the routine analysis of pitch and roll buoy wave data, J. Phys. Oceanogr., 18, 1020-1034, 1988.

Kumar, V. S.: Variation of wave directional spread parameters along the Indian coast, Appl. Ocean Res., 28, 98-103, 2006.

Kumar, V. S. and Anand, N. M.: Variations in wave direction estimated using first and second order Fourier coefficients, Ocean Eng., 31, 2105-2119, 2004.
Kumar, V. S., Deo, M. C., Anand, N. M., and Chandramohan, P.: Estimation of wave directional spreading in shallow water, Ocean Eng., 26, 83-98, 1999.

Kumar, V.S., Deo, M.C., Anand, N.M., and Kumar, K.A.: Directional spread parameter at intermediate water depth, Ocean Eng., 27(8), 889-905, 2000.

Kumar, V. S., Glejin, J., Dora, G. U., Philip, S. C., Singh, J., and Pednekar, P.: Variations in nearshore waves along Karnataka, west coast of India, J. Earth. Syst. Sci., 121, 393-403, 2012.

Kumar, V. S., Shanas, P. R., and Dubhashi, K. K.: Shallow water wave spectral characteristics along the eastern Arabian Sea, Natural Hazards, online first, doi:10.1007/s11069-013-0815-7, 2013.

Lee, C., Jung, J.-S., and Haller, M. C.: Asymmetry in Directional Spreading Function of Random Waves due to Refraction, J. Waterw. Port C.-ASCE, 136, 1-9, 2010.

Longuet-Higgins, M. S., Cartwright, D. E., and Smith, N. D.: Observations of the directional spectrum of sea waves using the motions of a floating buoy in Ocean Wave Spectra, Prentice Hall, New York, 111-136, 1963.

Mishra, A. K., Gnanaseelan, C., and Seetaramayya, P.: A study of rainfall along the west coast of India in relation to low level jet and air-sea interactions over the Arabian Sea, Curr. Sci., 87, 475-485, 2004.

Mitsuyasu, H., Tasai, F., Suhara, T., Mizuno, S., Ohkusu, M., Honda, T., and Rikiishi, K.: Observations of the directional spectrum of ocean waves using a cloverleaf buoy, J. Phys. Oceanogr., 5, 750-760, 1975

Pawka, S. S.: Island shadows in wave directional spectra, J. Geophys. Res., 88, 2579-2591, 1983.

Pettersson, H. and Kahma, K. K.: Directional measurements of wave growth in a short and narrow fetch geometry, J. Atmos. Ocean Sci., 10, 15-29, 2005, http://www.ocean-sci.net/10/15/2005/.

Phillips, O. M.: On some properties of the spectrum of windgenerated ocean waves, J. Mar. Res., 16, 231-240, 1958

Sajiv, P. C., Kumar, V. S., Glejin, J., Dora, G. U., and Vinayaraj, P.: Interannual and seasonal variations in near shore wave characteristics off Honnavar, west coast of India, Curr. Sci., 103, 286-292, 2012.

Tucker, M. and Pitt, E.: Waves in ocean engineering, O. E. Series, Elsev. Sci. Ltd., 548 pp., 2001.

Wang, D. W. and Hwang, P. A.: Evolution of the bimodal directional distribution of ocean waves, J. Phys. Oceanogr., 31, 1200-1221, 2001.

Wyatt, L. R.: The effect of fetch on the directional spectrum of Celtic Sea storm waves, J. Phys. Oceanogr., 25, 1550-1559, 1995.

Wyatt, L. R. and Van der Vlugt, T.: Estimating bimodal frequencydirection spectra from surface buoy data recorded during tropical cyclones, J. Offshore Mech. Arct., 121, 172-180, 1999.

Young, I. R., Verhagen, L. A., and Banner, M. L.: A note on the bimodal directional spreading of fetch-limited wind waves, J. Geophys. Res., 100, 773-778, 1995.

Zhang, S. and Zhang, J.: A new approach to estimate directional spreading parameters of a Cosine-2s model, J. Atmos. Ocean. Tech., 23, 297-301, 2006. 